\title{
p53 nuclear accumulation and ERo expression in ductal hyperplasia of breast in a cohort of 215 Chinese women
}

\author{
Xiao-yun Mao', Chui-feng Fan², Hua-chuan Zheng ${ }^{3}$, Jing Wei', Fan Yao' ${ }^{1}$ Feng Jin ${ }^{1 *}$
}

\begin{abstract}
Introduction: Women with ductal hyperplasia including usual ductal hyperplasia (UDH) and atypical ductal hyperplasia (ADH) have an increased risk of developing invasive ductal carcinoma (IDC) of breast. The importance of several molecular markers in breast cancer has been of considerable interest during recent years such as p53 and estrogen receptor alpha (ER $\alpha)$. However, p53 nuclear accumulation and ER $\alpha$ expression have not been assessed in ductal hyperplasia co-existing with ductal carcinoma in situ (DCIS) or IDC versus pure ductal hyperplasia without DCIS or IDC.

Materials and methods: We investigated p53 nuclear accumulation and ER $\alpha$ expression in breast ductal hyperplasia in a cohort of 215 Chinese women by immunohistochemistry (IHC), which included 129 cases of pure ductal hyperplasia, 86 cases of ductal hyperplasia co-existing with DCIS (41 cases) or IDC (45 cases).

Results: Nuclear p53 accumulation was identified in 22.8\% of ADH (31/136), 41.5\% of DCIS (17/41) and $42.2 \%$ of IDC (19/45), and no case of UDH (0/79). No difference in nuclear p53 accumulation was observed between pure $\mathrm{ADH}$ and $\mathrm{ADH}$ CO-existing with DCIS (ADH/DCIS) or IDC (ADH/IDC) $(P>0.05)$. The positive rate of ER $\alpha$ expression was lower in ADH $(118 / 136,86.8 \%)$ than that in UDH $(79 / 79,100 \%)(P<0.001)$, but higher than that in DCIS (28/ $41,68.3 \%)$ or IDC $(26 / 45,57.8 \%)$ respectively $(P<0.001)$. The frequency of ER $\alpha$ expression was lower in ADH/DCIS $(23 / 29,79.31 \%)$ and $\mathrm{ADH} / \mathrm{IDC}(23 / 30,76.67 \%)$ than that in pure $\mathrm{ADH}(72 / 77,93.51 \%)$ respectively $(P<0.05)$. There was a negative weak correlation between p53 nuclear accumulation and ER $\alpha$ expression as for ADH (coefficient correlation $-0.51 ; P<0.001)$.

Conclusions: Different pathological types of ductal hyperplasia of breast are accompanied by diversity in patterns of nuclear p53 accumulation and ER $\alpha$ expression. At least some pure ADH is molecularly distinct from ADH/CIS or $\mathrm{ADH} / \mathrm{IDC}$ which indicated the two types of $\mathrm{ADH}$ are molecularly distinct entities although they have the same morphological appearance.
\end{abstract}

\section{Introduction}

Worldwide, breast cancer comprises $10.4 \%$ of cancer incidence among women, making it the second most common type of non-skin cancer (after lung cancer) and the fifth most common cause of cancer death [1]. In the last two decades, the incidence and mortality of breast cancer have climbed sharply in China, thus attracting increased attention of researchers [2].

\footnotetext{
* Correspondence: jinfeng66cn@hotmail.com

'Department of Breast Surgery, Department of Surgical Oncology, Research Unit of General Surgery, the First Affiliated Hospital of China Medical

University, Shenyang, Liaoning Province, (110001), China

Full list of author information is available at the end of the article
}

Historically, beast cancer emerges by a multistep process which can be broadly equated to transformation of normal cells via the steps of hyperplasia, premalignant lesions and in situ carcinoma, invasive carcinoma which supported by evidences from clinical, pathological, and genetic studies [3-5]. It is a heterogeneous disease that encompasses a wide range of pathological entities and clinical behaviors, thus posing great challenges in understanding the precise molecular mechanisms of breast carcinogenesis [3]. Recent studies show that about $8 \%$ to $9 \%$ of women with benign lesions will be subsequently developed into invasive breast cancer [6,7]. It is quite unclear how invasive breast cancer develops through 
these ductal hyperplasias, which include usual ductal hyperplasia $(\mathrm{UDH})$ and atypical ductal hyperplasia $(\mathrm{ADH})[8]$.

The importance of some molecular markers in breast cancer has been of considerable interest during recent years, not only as prognostic markers, but also as predictors of response to therapy. p53 is the primary arbiter of the mammalian cells' response to stress. In its normal form, p53 can be involved in the induction of apoptosis and thus has a regulatory function over the cell cycle. In its mutant form, p53 inhibits apoptosis, loses control on cell cycle progression and thus helps tumor formation [9]. Nuclear p53 accumulation which associates with p53 mutation is one of the most common events during breast carcinogenesis [10-12]. Epidemiological and experimental evidences implicated oestrogens in the aetiology of breast cancer [13-17]. The biological actions of estrogens are mediated by binding to one of two specific estrogen receptors (ERs), ER $\alpha$ or ER $\beta$, which belong to a family of ligand-regulated transcription factors [18]. $E R \alpha$ has been widely accepted as a prognostic marker and a predictor for endocrine therapy response of breast cancer $[19,20]$. In general, ER $\alpha$-negative breast cancers are more aggressive and unresponsive to antiestrogens [21]. However, p53 nuclear accumulation and ER $\alpha$ expression have not been assessed in ductal hyperplasia co-existing with ductal carcinoma in situ (DCIS) or invasive ductal carcinoma (IDC) versus pure ductal hyperplasia without DCIS or IDC. The aims of this study were: (a) to assess p53 nuclear accumulation and ER $\alpha$ expression in pure ductal hyperplasia and ductal hyperplasia coexisting with DCIS or IDC; (b) to explore if there is a differential expression pattern of ER $\alpha$ and p53 nuclear accumulation between pure ductal hyperplasia and ductal hyperplasia co-existing with DCIS or IDC.

\section{Materials and methods}

Patients and tissues: 129 cases of pure ductal hyperplasia of breast, 86 cases of ductal hyperplasia co-existing with DCIS (41 cases) and IDC (45 cases) were collected from surgical samples of women at the First Affiliated Hospital of China Medical University between 2005 and 2010. None of patients undergo chemotherapy, radiotherapy or adjuvant treatment before operation. Patients' ages ranged from 21 to 82, with an average age of 43.8 years old. Each case was reviewed independently by 2 pathologists (Chui-feng Fan and Min Song) with a subspecialty focus in breast pathology, and only those cases that both pathologists finally reached the unanimous diagnosis were used. In case of insufficient or unattainable material, original tissue blocks were reprocessed and new slides were created. The pathological types of breast ductal hyperplasia lesions have been classified according to WHO's criteria which published by
Table 1 Breast ductal hyperplasia lesions of the different pathological types

\begin{tabular}{lcccc}
\hline & Pure type & With DCIS & With IDC & Total \\
\hline UDH & 52 & 12 & 15 & 79 \\
ADH & 77 & 29 & 30 & 136 \\
DIN 1A & 1 & 9 & 6 & 16 \\
DIN 1B & 76 & 20 & 24 & 120 \\
Total & 129 & 41 & 45 & 215 \\
\hline
\end{tabular}

Tavassoli FA et al [22]. All sections were reviewed for a comprehensive list of pathologic features, including margins (close margins were defined as tissue-free margins $<1 \mathrm{~mm}$ ), the presence of concomitant UDH, ADH, DCIS and IDC. The pathological types of breast ductal hyperplasia lesions were summarized in Table 1 . The cases of breast ductal hyperplasia lesions include 79 cases of UDH and 136 cases of ADH (16 cases of ductal intraepithelial neoplasia 1A (DIN 1A) and 120 cases of ductal intraepithelial neoplasia 1B (DIN 1B)). The study was approved by the regional ethics committee at China Medical University.

Immunohistochemistry: Formalin-fixed and paraffinembedded specimens were cut into $4 \mu \mathrm{m}$-thick sections, which were subsequently de-waxed and hydrated. Immunohistochemical staining for ER $\alpha$ (sc-542, Santa Cruz, 1:200) and p53 (sc-47698, Santa Cruz, 1:100) were performed using UltraSensitive ${ }^{\mathrm{Tw}}$ S-P kits (Maixin-Bio; P.R. China) according to the manufacturer's instructions and using the reagent supplied within the kit. For the negative control, phosphate-buffered saline (PBS) was used in place of the primary antibodies. We also adopted the German semi-quantitative scoring system in considering the staining intensity and area extent, which has been widely accepted and used in previous studies [23-25]. Every lesions was given a score according to the intensity of the nucleic staining (no staining $=0$, weak staining $=1$, moderate staining $=2$, strong staining $=3$ ) and the extent of stained cells $(0 \%=0,1-10 \%=1$, $11-50 \%=2,51-80 \%=3,81-100 \%=4$; negative means $0 \%$ area staining, focally positive means $1-80 \%$ area staining, diffusely positive means $81-100 \%$ area staining). The final immunoreactive score was determined by multiplying the intensity scores with the extent of positivity scores of stained cells, with the minimum score of 0 and a maximum score of 12 [24-26]. Slides were independently examined by 2 pathologists (Chui-feng Fan and Min Song) as previously mentioned; however, if there was a discrepancy in individual scores both pathologists reevaluated together by reaching a consensus agreement before combining the individual scores. To obtained statistical results, a final score equal to or less than 1 was considered as negative, while scores of 2 or more were considered as positive. 
Statistical analysis: The results were evaluated using the $\chi 2$ test. The correlation between p53 nuclear accumulation and ER $\alpha$ expression was tested by using the Pearson chi-square test. All statistical analyses were performed using SPSS 13.0 for Windows (SPSS Inc., Chicago, IL, USA). Statistical significance in this study was set at $\mathrm{P}<0.05$. All reported $\mathrm{P}$ values are two-sided.

\section{Results}

p53 nuclear accumulation in ductal hyperplasia of breast The phenotypic expression patterns of p53 in breast ductal hyperplasia were shown in Figure 1. Table 2 showed p53 nuclear accumulation in ductal hyperplasia of breast. No p53 nuclear accumulation was found in UDH (0/79) regardless of co-existing DCIS or IDC. p53 nuclear accumulation was detectable in $22.8 \%$ of ADH $(31 / 136)$, higher than that in UDH $(P<0.001)$, lower than that in DCIS $(41.5 \%, 17 / 41)$ or in IDC $(42.2 \%, 19 / 45)$ respectively $(P<0.01)$. No difference in nuclear p53 accumulation were observed between pure ADH (14/77) and ADH/DCIS (9/29) (18.2\% vs. $31.0 \%$, $P>0.05)$ or ADH/IDC $(8 / 30)(18.2 \%$ vs. $26.7 \%$, $P>0.05)$.
ER $\alpha$ expression in ductal hyperplasia of breast

The phenotypic expression patterns of ER $\alpha$ protein in breast ductal hyperplasia were shown in Figure 2. The positive rate of ER $\alpha$ expression in breast ductal hyperplasia was summarized in Table 2.The positive rate of ER $\alpha$ expression was lower in ADH $(118 / 136,86.8 \%)$ than that in UDH $(79 / 79,100 \%)(P<0.001)$, but higher than that in DCIS $(28 / 41,68.3 \%)$ or IDC $(26 / 45,57.8 \%)$ respectively $(P<0.001)$. The frequency of ER $\alpha$ expression was lower in ADH/DCIS (23/29, 79.31\%) and ADH/IDC (23/30, 76.67\%) than that in pure ADH (72/ $77,93.51 \%)$ respectively $(P<0.05)$.

\section{Correlation between p53 nuclear accumulation and ER $\alpha$ expression}

There was no correlation between p53 nuclear accumulation and $E R \alpha$ expression in any type of ductal hyperplasia of breast $(P>0.05)$. But as shown in Figure 3. p53 nuclear accumulation and ER $\alpha$ expression had inverse patterns of alterations in $\mathrm{ADH}$ of breast. As for ADH, which shown in Table 3 the correlation coefficient was -0.512 between p53 nuclear accumulation and ER $\alpha$ expression $(P<0.001)$.

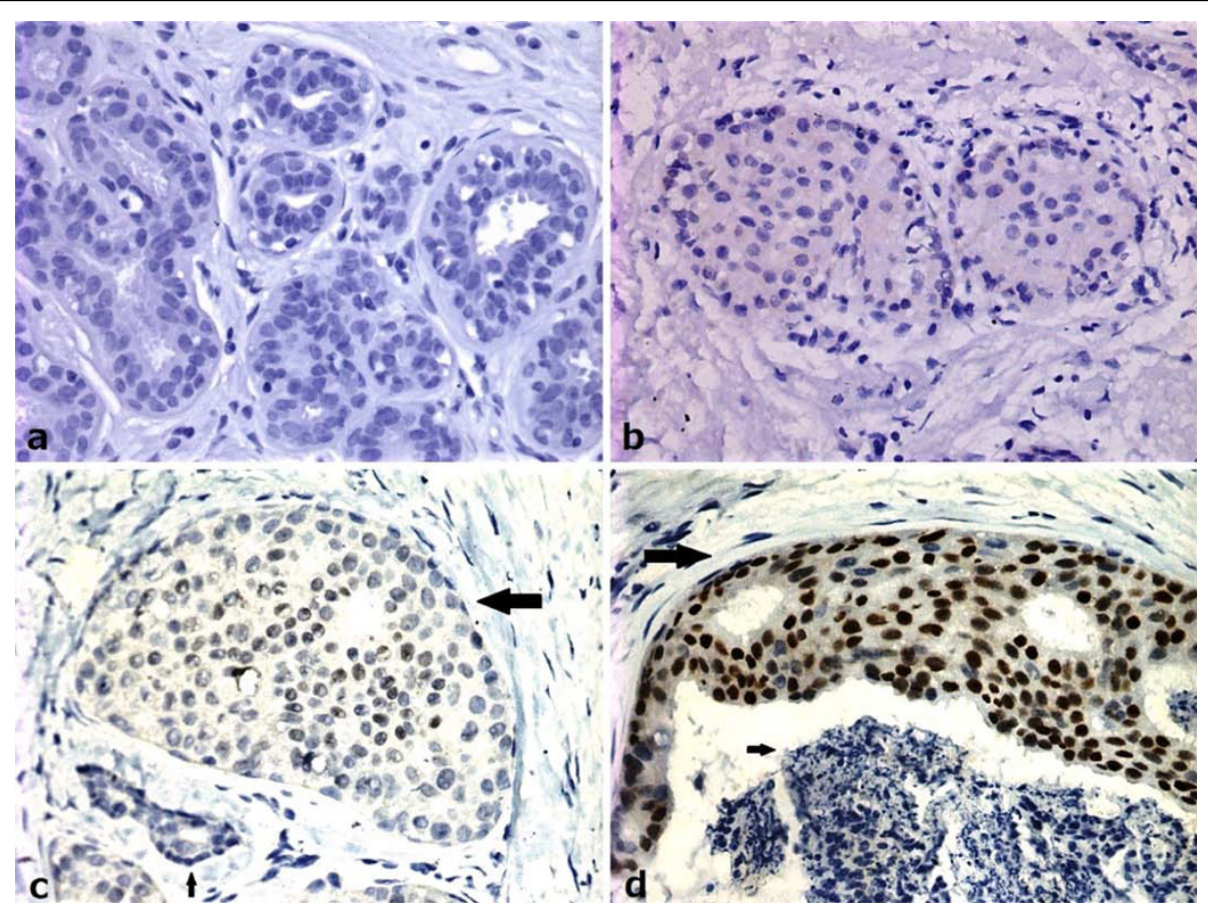

Figure 1 Immunohistochemical staining of noninvasive breast lesions with antibody against p53. p53 nuclear accumulation was not found in epithelial cells of normal ducts (a) and usual ductal hyperplasia (b) of breast. p53 positive staining in atypical ductal hyperplasia (c): the bigger arrow shows a breast duct filled with cells with atypical hyperplasia. The cells are quite identical in size and shape. Staining of p53 is seen in some nuclears (> 10\%). The little arrow shows a normal duct without p53 nuclear accumulation. p53 positive staining in ductal carcinoma in situ (d): the bigger arrow shows a ductal carcinoma in situ with positive staining of p53 in nuclears (> 10\%). The little arrow shows necrosis in the ductal carcinoma in situ. $(\times 40)$ 
Table 2 p53 nuclear accumulation and ER $\alpha$ expression in ductal hyperplasia of breast

\begin{tabular}{|c|c|c|c|c|c|c|c|}
\hline & \multirow[t]{2}{*}{ Total no. } & \multicolumn{2}{|c|}{ p53 nuclear accumulation } & \multirow[t]{2}{*}{ P-value } & \multicolumn{2}{|c|}{ ER $\alpha$ expression } & \multirow[t]{2}{*}{ P-value } \\
\hline & & + & - & & + & - & \\
\hline \multicolumn{8}{|l|}{ UDH } \\
\hline Pure type & 52 & 0 & 52 & $>0.05$ & 52 & 0 & $>0.05$ \\
\hline With DCIS & 12 & 0 & 12 & & 12 & 0 & \\
\hline With IDC & 15 & 0 & 15 & & 15 & 0 & \\
\hline \multicolumn{8}{|l|}{$\mathrm{ADH}$} \\
\hline Pure type & 77 & 14 & 63 & $>0.05$ & 72 & 5 & $<0.05$ \\
\hline With DCIS & 29 & 9 & 20 & $\chi^{2}=2.31$ & 23 & 6 & $\chi^{2}=7.12$ \\
\hline With IDC & 30 & 8 & 22 & & 23 & 7 & \\
\hline \multicolumn{8}{|l|}{ DCIS } \\
\hline With UDH & 12 & 5 & 7 & $>0.05$ & 8 & 4 & $>0.05$ \\
\hline With ADH & 29 & 12 & 17 & $\chi^{2}=0.00$ & 20 & 9 & $\chi^{2}=0.00$ \\
\hline \multicolumn{8}{|l|}{ IDC } \\
\hline With UDH & 15 & 7 & 8 & $>0.05$ & 11 & 4 & $>0.05$ \\
\hline With ADH & 30 & 12 & 18 & $\chi 2=0.18$ & 15 & 15 & $\chi 2=1.38$ \\
\hline
\end{tabular}

\section{Discussion}

p53 is located on human chromosome $17 \mathrm{p}$ and its encoding protein mediates its tumor suppressor function $v i a$ the transcriptional regulation or repression of various genes [26-29]. p53 had been suggested to be predictive of risk for subsequent breast carcinogenesis, p53 nuclear accumulation has been identified as a poor prognostic marker in breast cancer [30]. The immunohistochemical detection of nuclear p53 protein accumulation is highly associated with p53 gene mutations in breast cancer tissues [31], in benign breast lesions it has been associated with elevated risk of progression to

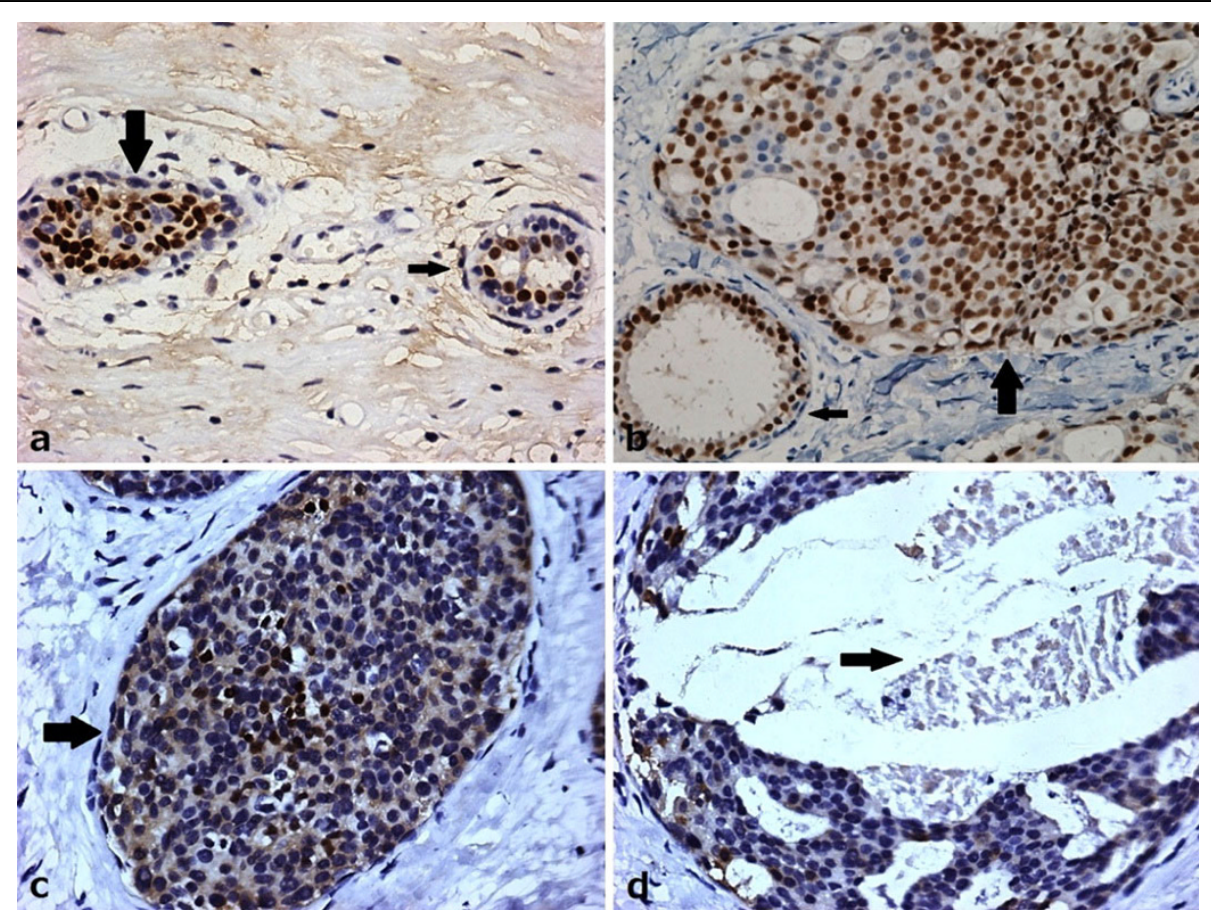

Figure 2 ER $\alpha$ expression in noninvasive breast lesions. a: ER $\alpha$ staining in epithelial cells of normal ducts (smaller arrow) and usual ductal hyperplasia (bigger arrow) of breast was located in nuclear. b: ERo staining was seen in all epithelial cells of a normal duct (smaller arrow) but was reduced in cells in a co-existing duct with atypical ductal hyperplasia (bigger arrow). c: The arrow shows a breast duct with atypical ductal hyperplasia with positive staining of ER $\alpha(>10 \%)$ which was absent in some cells. $d$ : ER $\alpha$ staining in a ductal carcinoma in situ was negative $(<10 \%)$. The arrow shows the necrosis. $(\times 40)$ 


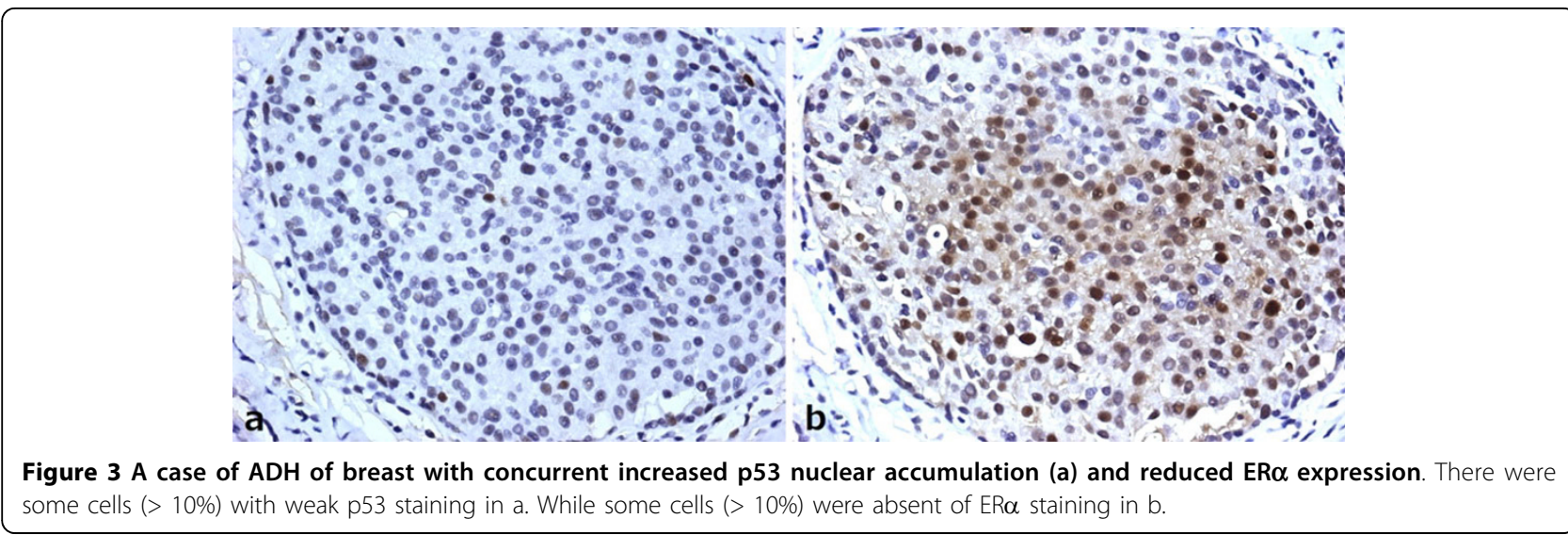

breast cancer [32]. In this study, we found nuclear p53 accumulation occurred in ADH but not in UDH regardless of co-existing DCIS or IDC. Nuclear p53 accumulation was not significantly different between pure ADH and ADH co-existing DCIS or IDC. It was in accordance with previous studies that UDH was considered to represent a benign proliferation of ductal epithelial cells, whereas ADH represents the first clonal neoplastic expansion of these cells [33]. It is clear that not all ADH will progress into DCIS or IDC during the patient's lifetime. However, we found no differences in p53 expression between pure ADH and ADH co-existing with DCIS or IDC. Maybe there are more molecular alteration counteracts with p53 or p53 itself is an initiative factor in breast carcinogenesis.

Epidemiological and experimental evidences implicated estrogens in the aetiology of breast cancer which play a central role in the growth and differentiation of normal breast epithelium [13-17]. ER $\alpha$ status has also been shown to have prognostic value in breast cancer, although the importance of hormone-receptor status lies rather as a predictor of response to endocrine therapy. A potential mechanism of hormone resistance is the acquired loss of ER $\alpha$ gene expression at the transcriptional level during breast carcinogenesis [34-37]. Here, we found ER $\alpha$ expression in all UDH regardless of coexisting DCIS or IDC though there were occasionally sporadic staining patterns, and there was significant loss of ER $\alpha$ expression in ADH and breast carcinoma, ER $\alpha$

Table 3 Correlation of p53 nuclear accumulation with ER? expression in ADH

\begin{tabular}{|c|c|c|c|}
\hline & \multicolumn{2}{|c|}{ p53 unclear accumulation } & \\
\hline & + & - & \\
\hline ER $\alpha$ expression + & 17 & 101 & $r=-0.512$ \\
\hline ER $\alpha$ expression - & 14 & 4 & $P<0.001$ \\
\hline
\end{tabular}

Correlation between p53 nuclear accumulation and ER $\alpha$ expression; $r=$ correlation coefficient $(n=136)$. was decreasingly expressed from UDH to ADH, DCIS or IDC. Our findings support that UDH and ADH are different ductal hyperplasia lesions of breast, they have pathological types which accompanied by diversity in pattern of genetic expression.

In our study, a significant difference in ER $\alpha$ expression was found between pure type ADH and ADH/ DCIS or ADH/IDC, suggested that the subsets of ADH/ $\mathrm{CIS}$ or ADH/IDC may have different molecular genetics in comparison with the pure ADH without DCIS or IDC. ADH and ADH/DCIS or ADH/IDC have similar morphology, but have different ER $\alpha$ expression. Furthermore, we found a negative weak correlation between p53 nuclear accumulation and ER $\alpha$ expression as for ADH (coefficient correlation -0.512; $P<0.001$ ). Experiments in vitro suggested that ER $\alpha$ opposes p53mediated apoptosis in breast cancer cells by Sayeed A [38]. Shirley SH performed animal experiments to show that p53 genotype was correlated with ER expression and response to tamoxifen in mammary tumors arising in mouse mammary tumor virus-Wnt-1 transgenic mice. They changed the p53 expression of MCF-7 cells with doxorubicin or ionizing radiation, ER expression was also changed. In MCF-7 transfected with WT p53, transcription from the ER promoter was increased 8-fold, they concluded that p53 may regulate ER expression [39]. Based on our study, further investigation about the relation between p53 and ER appear to be warranted in breast carcinogenesis.

$\mathrm{ER} \alpha$ loss in breast carcinoma is considered an unfavorable factor for patients partly due to the accordingly reduced sensitivity of cancer cells to endocrine therapy. There are patients with ER $\alpha$ (-) breast carcinomas but has ER $\alpha(+)$ surrounding breast tissues including those have atypical hyperplasia. These patients are often not supposed to be given the endocrine therapy. But what the ER $\alpha(+)$ surrounding breast tissues means to the endocrine therapy protocol is still mysterious and intriguing. Based on our study, ER $\alpha$ loss may be partly due 
to p53 accumulation during carcinogenesis of breast carcinoma. On the other hand there also may be some other unknown molecules involved in the interplays with ER $\alpha$ loss instead of p53 nuclear accumulation. To restore the ER $\alpha(+)$ phenotype of breast carcinogenesis for better outcome of endocrine therapy, further investigation of molecules involved is necessary.

In summary, we found the diversity of the pathological type is accompanied by diversity in pattern of genetic expression. And at least some pure ADH is molecularly distinct from ADH/CIS or ADH/IDC which indicated the two types of ADH are molecularly distinct entities although they have the same morphological appearance. Molecular differences between pure and synchronous lesions support re-evaluation of current models of breast cancer initiation, progression, and risk.

\section{Acknowledgements}

This work was supported by National Natural Science Foundation of China (No. 30950009).

\section{Author details \\ 'Department of Breast Surgery, Department of Surgical Oncology, Research Unit of General Surgery, the First Affiliated Hospital of China Medical University, Shenyang, Liaoning Province, (110001), China. ${ }^{2}$ Department of Pathology, the First Affiliated Hospital and College of Basic Medical Sciences of China Medical University, Shenyang, (110001), China. ${ }^{3}$ Department of Biochemistry and Molecular Biology, College of Basic Medical Sciences of China Medical University, Shenyang, (110001), China.}

\section{Authors' contributions}

$\mathrm{JF}$ and MXY designed the research and wrote the paper. MXY and FCF collected the breast lesion tissues and carried out experiments. WJ, ZHC and YF analyzed the data. All authors have read and approved the manuscript.

\section{Competing interests}

The authors declare that they have no competing interests.

Received: 11 July 2010 Accepted: 16 August 2010

Published: 16 August 2010

\section{References}

1. Boyle P, Levin B: World Cancer Report. International Agency for Research on Cancer 2003

2. Liu Y, Ji R, Li J, Gu Q, Zhao X, Sun T, Wang J, Li J, Du Q, Sun B: Correlation effect of EGFR and CXCR4 and CCR7 chemokine receptors in predicting breast cancer metastasis and prognosis. J Exp Clin Cancer Res 2010, 29:16.

3. Steinman S, Wang J, Bourne P, Yang Q, Tang P: Expression of cytokeratin markers, ER-alpha, PR, HER-2/neu, and EGFR in pure ductal carcinoma in situ (DCIS) and DCIS with co-existing invasive ductal carcinoma (IDC) of the breast. Ann Clin Lab Sci 2007, 37:127-134.

4. Liu T, Niu Y, Yu Y, Liu Y, Zhang F: Increased gamma-tubulin expression and P16INK4A promoter methylation occur together in preinvasive lesions and carcinomas of the breast. Ann Oncol 2009, 20:441-448.

5. Arpino G, Laucirica R, Elledge RM: Premalignant and in situ breast disease: biology and clinical implications. Ann Intern Med 2005, 143:446-457.

6. Hartmann LC, Sellers TA, Frost MH, Lingle WL, Degnim AC, Ghosh K, Vierkant RA, Maloney SD, Pankratz VS, Hillman DW, Suman VJ, Johnson J, Blake C, TIsty T, Vachon CM, Melton LJ, Visscher DW: Benign breast disease and the risk of breast cancer. N Engl J Med 2005, 353:229-237.

7. Worsham MJ, Abrams J, Raju U, Kapke A, Lu M, Cheng J, Mott D, Wolman SR: Breast cancer incidence in a cohort of women with benign breast disease from a multiethnic, primary health care population. Breast J 2007, 13:115-121.
8. Poola I, Abraham J, Marshalleck JJ, Yue Q, Lokeshwar VB, Bonney G, Dewitty RL: Molecular risk assessment for breast cancer development in patients with ductal hyperplasias. Clin Cancer Res 2008, 14:1274-1280.

9. Ranade KI, Nerurkar AV, Phulpagar MD, Shirsat NV: Expression of survivin and p53 proteins and their correlation with hormone receptor status in Indian breast cancer patients. Indian J Med Sci 2009, 63:481-490.

10. Zhang Z, Wang M, Wu D, Wang M, Tong N, Tian Y, Zhang Z: P53 codon 72 polymorphism contributes to breast cancer risk: a meta-analysis based on 39 case-control studies. Breast Cancer Res Treat 2010, 120:509-517.

11. Rossner P Jr, Gammon MD, Zhang YJ, Terry MB, Hibshoosh H, Memeo L, Mansukhani M, Long CM, Garbowski G, Agrawal M, Kalra TS, Gaudet MM, Teitelbaum SL, Neugut Al, Santella RM: Mutations in p53, p53 protein overexpression and breast cancer survival. J Cell Mol Med 2009, 13:3847-3857.

12. Sarid D, Ron IG, Shoshan L, Barnea I, Shina S, Baratz M, Greenberg J, Merimsky O, Ben-Yosef R, Lev-Ari S, Keidar Y, Yaal-Hahoshen N: Invasive breast cancer treated with taxol and epirubicin neo-adjuvant chemotherapy: the role in the outcome of the "crosstalk" between Erb receptors and p53. Anticancer Res 2008, 28:3147-3152.

13. Travis RC, Key TJ: Oestrogen exposure and breast cancer risk. Breast Cancer Res 2003, 5:239-247.

14. Willems P, De Ruyck K, Van den Broecke R, Makar A, Perletti G, Thierens H, Vral A: A polymorphism in the promoter region of Ku70/XRCC6, associated with breast cancer risk and oestrogen exposure. J Cancer Res Clin Oncol 2009, 135:1159-1168.

15. Cheng AS, Culhane AC, Chan MW, Venkataramu CR, Ehrich M, Nasir A, Rodriguez BA, Liu J, Yan PS, Quackenbush J, Nephew KP, Yeatman TJ, Huang TH: Epithelial progeny of estrogen-exposed breast progenitor cells display a cancer-like methylome. Cancer Res 2008, 68:1786-1796.

16. Duss S, André S, Nicoulaz AL, Fiche M, Bonnefoi H, Brisken C, lggo RD: An oestrogen-dependent model of breast cancer created by transformation of normal human mammary epithelial cells. Breast Cancer Res 2007, 9:R38.

17. Polyak K: Breast cancer: origins and evolution. J Clin Invest 2007, 117:3155-3163.

18. Matthews J, Gustafsson JA: Estrogen signaling: a subtle balance between ER alpha and ER beta. Mol Interv 2003, 3:281-292.

19. Dunnwald LK, Rossing MA, Li Cl: Hormone receptor status, tumor characteristics, and prognosis: a prospective cohort of breast cancer patients. Breast Cancer Res 2007, 9:R6.

20. Goldhirsch A, Gelber RD, Coates AS: What are the long-term effects of chemotherapy and hormonal therapy for early breast cancer? Nat Clin Pract Oncol 2005, 2:440-441.

21. Chen JQ, Russo J: ERalpha-negative and triple negative breast cancer: molecular features and potential therapeutic approaches. Biochim Biophys Acta 2009, 1796:162-175.

22. Tavassoli FA: Breast pathology: rationale for adopting the ductal intraepithelial neoplasia (DIN) classification. Nat Clin Pract Oncol 2005, 2:116-117.

23. Kok LF, Lee MY, Tyan YS, Wu TS, Cheng YW, Kung MF, Wang PH, Han CP: Comparing the scoring mechanisms of p16INK4a immunohistochemistry based on independent nucleic stains and independent cytoplasmic stains in distinguishing between endocervical and endometrial adenocarcinomas in a tissue microarray study. Arch Gynecol Obstet 2010, 281:293-300.

24. Koo CL, Kok LF, Lee MY, Wu TS, Cheng YW, Hsu JD, Ruan A, Chao KC, Han CP: Scoring mechanisms of p16INK4a immunohistochemistry based on either independent nucleic stain or mixed cytoplasmic with nucleic expression can significantly signal to distinguish between endocervical and endometrial adenocarcinomas in a tissue microarray study. J Transl Med 2009, 7:25.

25. Manne U, Myers RB, Moron C, Poczatek RB, Dillard S, Weiss H, Brown D, Srivastava S, Grizzle WE: Prognostic significance of Bcl-2 expression and p53 nuclear accumulation in colorectal adenocarcinoma. Int I Cancer 1997, 74:346-358.

26. Toledo F, Wahl GM: Regulating the p53 pathway: in vitro hypotheses, in vivo veritas. Nat Rev Cancer 2006, 6:909-923.

27. Green DR, Chipuk JE: p53 and metabolism: Inside the TIGAR. Cell 2006, 126:30-32.

28. Bocangel D, Sengupta S, Mitra S, Bhakat KK: p53-Mediated downregulation of the human DNA repair gene O6-methylguanine-DNA 
methyltransferase (MGMT) via interaction with $\mathrm{Sp} 1$ transcription factor. Anticancer Res 2009, 29:3741-3750.

29. Thompson AM, Lane DP: p53 transcriptional pathways in breast cancer: the good, the bad and the complex. J Pathol 2010, 220:401-403.

30. Dookeran KA, Dignam JJ, Ferrer K, Sekosan M, McCaskill-Stevens W, Gehlert S: p53 as a marker of prognosis in African-American women with breast cancer. Ann Surg Oncol 2010, 17:1398-1405.

31. Fan $P$, Wu Z, Cha $X$, Wang $X$, Wang S: Comparison of nuclear accumulation of $p 53$ protein with mutations in the p53 gene on the tissues of human breast cancer. Zhonghua Wai Ke Za Zhi 1998, 36:655-657.

32. Rohan TE, Li SQ, Hartwick R, Kandel RA: $p 53$ Alterations and protein accumulation in benign breast tissue and breast cancer risk: a cohort study. Cancer Epidemiol Biomarkers Prev 2006, 15:1316-1323.

33. Gong G, DeVries S, Chew KL, Cha I, Ljung BM, Waldman FM: Genetic changes in paired atypical and usual ductal hyperplasia of the breast by comparative genomic hybridization. Clin Cancer Res 2001, 7:2410-2414.

34. Pinzone JJ, Stevenson H, Strobl JS, Berg PE: Molecular and cellular determinants of estrogen receptor alpha expression. Mol Cell Biol 2004, 24:4605-4612.

35. McLaren BK, Gobbi H, Schuyler PA, Olson SJ, Parl FF, Dupont WD, Page DL: Immunohistochemical expression of estrogen receptor in enlarged lobular units with columnar alteration in benign breast biopsies: a nested case-control study. Am J Surg Pathol 2005, 29:105-108.

36. Spears $M$, Bartlett J: The potential role of estrogen receptors and the SRC family as targets for the treatment of breast cancer. Expert Opin Ther Targets 2009, 13:665-674.

37. Zagouri F, Sergentanis TN, Zografos GC: Precursors and preinvasive lesions of the breast: the role of molecular prognostic markers in the diagnostic and therapeutic dilemma. World I Surg Oncol 2007, 5:57.

38. Sayeed A, Konduri SD, Liu W, Bansal S, Li F, Das GM: Estrogen receptor alpha inhibits p53-mediated transcriptional repression: implications for the regulation of apoptosis. Cancer Res 2007, 67:7746-7755.

39. Shirley SH, Rundhaug JE, Tian J, Cullinan-Ammann N, Lambertz I, Conti CJ, Fuchs-Young R: Transcriptional regulation of estrogen receptor-alpha by p53 in human breast cancer cells. Cancer Res 2009, 69:3405-3414.

doi:10.1186/1756-9966-29-112

Cite this article as: Mao et al: p53 nuclear accumulation and ER $\alpha$ expression in ductal hyperplasia of breast in a cohort of 215 Chinese women. Journal of Experimental \& Clinical Cancer Research 2010 29:112.

\section{Submit your next manuscript to BioMed Central and take full advantage of:}

- Convenient online submission

- Thorough peer review

- No space constraints or color figure charges

- Immediate publication on acceptance

- Inclusion in PubMed, CAS, Scopus and Google Scholar

- Research which is freely available for redistribution 